Article

\title{
Smart City as a Tool of Citizen-Oriented Urban Regeneration: Framework of Preliminary Evaluation and Its Application
}

\author{
Jooseok Oh $\mathbb{D}$ \\ Department of Architecture, Korea University, Seoul 02841, Korea; ohjooseok@korea.ac.kr
}

Received: 17 July 2020; Accepted: 21 August 2020; Published: 24 August 2020

check for updates

\begin{abstract}
This study explores projects to regenerate old urban spaces and introduce smart city systems. It focuses on citizen perspectives and ways to build a citizen-centered smart city. A survey of 624 residents was undertaken in three South Korean cities where relevant projects have been implemented. The Hierarchical Regression Model was employed to learn what factors affect citizens' overall preferences for smart city projects. The analysis found that citizens prefer the services closely linked to their everyday lives, and that those with lower quality of life regarding housing circumstances and safety show greater interest in smart city projects, albeit there are differences among the cities. They also view and prefer those projects as a means of resolving everyday problems and local economic development, rather than seeking specific technologies or devices. Based on these results, this research presents implications and suggestions to link urban regeneration plans to smart city projects.
\end{abstract}

Keywords: smart city; urban regeneration; smart citizen; urban degradation; regression model

\section{Introduction}

Citizens have become a point of emphasis in the discourse surrounding smart cities, following its increasing focus on technocratic and instrumental aspects in the early 2000s. There are several reasons for relating the two elements-citizens and smart cities-which have long been considered as being completely separated; these include changes in the perceptions of both public and civil entities with regard to smart cities in policy, economic, and social terms, but these can be largely narrowed down into two perspectives.

First, we must highlight citizen-centric smart city initiative, which promotes the importance of citizens' political and social participation for implementing a smart city project based on planning, management, and stewardship [1]. The second point concerns the importance of supplying sustainable smart city services in response to citizens' demands to improve their quality of life [2]. Accordingly, in the urban planning field, citizen and community inputs have been emphasized in the planning and designing of smart cities' physical environments-for example, the establishment of a community-level service [3]. This indicates that a smart city of the date should address two challenges: a complete consideration of civil societies when deploying smart city technologies and facilities in urban spaces, and the supply of appropriate services for meeting citizens' needs.

To meet these goals, recent studies have been working to help citizens access smart city technologies. Two factors make this possible: (1) A smart city project is primarily applied within existing urban facilities based on established urban planning methodologies and related policy measures [4] and (2) Several researchers have found that smart city technologies can directly affect citizens' behaviors and their ability to lead sustainable lives [5]. However, practical studies that can best describe the relationship between smart cities and citizens' lives have remained scarce [6]. It might be natural that 
traditional urban planning has limitations in fully encompassing smart city projects. While smart city-related technologies continue to emerge and advance, urban planning has been built over the past decades on the basis of citizens' participation, citizen-oriented services, and infrastructures and their supply systems, among other things. The types and scopes of smart city technologies differ, and similarly, types of urban planning also vary based on certain business factors. This is why several researches that aim at finding a middle ground for reflecting both smart city projects and urban planning are underway, and multiple studies, including [7], explore smart cities in the real world-not just in theoretical terms.

Accordingly, some major recent case studies have defined a smart city as "a means of changing infrastructures and services of cities from the perspectives of economy, environment, transportation, and governance technology" [8]; "introduction of Information and Communication Technologies (ICT) infrastructure to urban places to improve the quality of life" [9]; and "socio-economic development by maximizing new innovative technologies from citizens' viewpoint" [10]. Along with the growing trend of highlighting citizens' roles in smart city projects, multiple researches, including [11,12], reviewed smart cities as tools for regenerating established cities; recently, this view has been expanded further by researchers such as $[13,14]$ to suggest that smart cities could contribute toward the preservation of local identities, and physical and social heritage contexts. These studies share similarities because they ultimately recognize and claim smart cities as a means of improving citizens' quality of life. However, depending on urban residents' features, each urban planning type, as a practical methodology for analyzing a smart city, shows clear differences in terms of process and outcome [15]. The results could also vary depending on the type of goods used in each subject area, each areas' capital and policy measures [16], and the economic background of each nation [17].

Despite continued discussions, most research aiming to put urban planning and smart cities on the same page has largely been confined to reviewing and monitoring the results. Such limitations indicate that it is desirable to view these issues as matters involving citizens' quality of life, analyze and compare cases involving diverse spatial backgrounds, and consider both physical and social circumstances; all of these imply that smart city projects should focus on their starting point and a series of procedures rather than on the end product.

Accordingly, this study selected three cities where government-led urban regeneration and smart city establishment projects were being implemented at the same time; this study aimed to identify the types of technologies, facilities, and services citizens preferred regarding these projects. Furthermore, this study also examined whether and - if so-how much smart city technologies, facilities, and services affected their preference (as a means for improving users' quality of life) and users' socio-economic characteristics. Based on this analysis, this paper sought to present some research implications for this field.

\section{Literature Review}

\subsection{Smart City as a Quality of Life Enhancement Tool in Urban Planning}

The current definition of "smart" city, which is a neutral term that involves both human and material factors, has undergone several changes in terms of concept and name including "intelligent," "information," "wired," "knowledge," and "digital" city [18]; furthermore, these terms mainly reflect the objectives of introducing specific technologies to a city [19]. Though discussions about smart cities have touched upon the roles of citizens, residents' quality of life (involving both objective and subjective aspects) began to be considered in a specific manner only in the mid-2010s. Beginning around this time, several studies began to call for the realization of citizen-centric smart cities-not for introducing new technologies but for improving quality of life-though the impacts of social, physical, and environmental development, revitalization, or regeneration of urban spaces on people's life quality have been confirmed by diverse earlier researches such as [20-23], both quantitatively and qualitatively. 
A slew of domains and indicators can be used for measuring urban dwellers' quality of life in a proper manner, so it is necessary to choose ones that suit the circumstances of each city and their different business types [23]. Regarding these, several studies on citizen-centric urban planning found that "Subjective Quality of Life," which is evaluated by each resident, suggested implications for resolving local problems. The major indicators used by researches on this vary, but they can be classified into four categories.

The first aspect involves subjective health issues; these are assessed based on the assumption that each city's overall physical and social health can be measured by evaluating individual citizens' mental and physical conditions [24]. In the same context, subjective health is widely used in researches involving large cities, such as Taipei and Singapore [24-26], and rural areas. The second aspect involves subjective safety evaluation. Though the crime and crime-related death rates are mainly used for comparing cities' competitiveness, the general level of subjective safety is under consideration here to evaluate living and urban environments as a whole. Many studies, such as [27-29], have used this method as an evaluation indicator for gauging urban dwellers' life quality and community safety. The third aspect involves the urban environment; it evaluates citizens' satisfaction with the physical, natural, and environmental circumstances of residential areas and communities. Researches, such as [30-32], used these factors in their research models to emphasize that these models could be used as effective tools for learning users' evaluations of various urban environments. The final aspect involves the measurement of the subjective quality of a given residential environment. Residential space has long been regarded as a minimum unit for activities of individuals and families as well as community formation; furthermore, this affects general evaluations of their city. Studies, such as [33-35], have stressed that residents' physical and social satisfaction with housing is a crucial factor in measuring their subjective quality of life.

Measuring subjective quality of life (as mentioned above) involves single or multiple evaluation items and indicates the human-environment relationship when selecting domains for urban researches [35,36]. This shows that a comprehensive consideration of "human factors" as well as "physical and environmental circumstances" is necessary when examining such topics. Multiple studies, including [37], have stressed that smart cities should be evaluated by considering both physical and social perspectives, especially when listening to citizens based on urban study-oriented domains.

Thus, subjective quality of life is considered an efficient means for listening to citizens in existing cities; this indicator can support strategies for maintaining and further improving existing urban areas when fully considered along with a city's physical, natural, and environmental conditions. Therefore, this paper aimed to review the physical and environmental conditions of the selected city and, at the same time, assess citizens' quality of life; it also aimed to present new strategies for existing urban spaces.

\subsection{Smart City Technologies, Facilities, and Services}

Quality of life can be used for measuring physical infrastructures or facilities as well as social ties based on citizens' perspectives in a comprehensive manner. However, if a plan considers citizen-oriented vision while creating actual urban spaces with physical and social infrastructure, listening to public opinions should accompany the evaluation or their preference for them. Noteworthily, the classification of smart city-related goods is far from clear in the urban planning field due to rapidly changing technologies and policy environments. Smart city-oriented goods should also be selected in advance when urban planning preparations are made; citizens' opinions should be reviewed beforehand with consideration of factors such as equipment, the necessary capacity for electricity, and storage facilities for processing and preserving data. Regarding urban renewal projects that aim to maintain and inherit an existing city's organizations and communities, in particular, the classification and presentation of smart city supplies, will become a barometer and roadmap for establishing related policies, such as those involving their maintenance, management, and service improvements in the future. 
As classification criteria for establishing such a roadmap, Lee, J.H., et al. [38] proposed the employment of the "service-device-technology (SDT)" framework. Here, the SDT presents classifications for currently applicable or under-development technologies; service contents based upon these technologies and target goals; and the equipment and device classifications that facilitate each technology and service. However, the range of devices presented here is not wide enough for application to actual construction and urban planning projects. If a device is replaced by the urban facility, this can be used as a domain that includes the technologies and services of a smart city as well as urban planning businesses. As highlighted by multiple researches, such as Lytras and Visvizi [39] and Chang and Lo [40], this focus implies that turning an established city into a smart one requires the advancement of existing architecture and urban planning facilities. Furthermore, comprehensive policy measures, such as unit planning and urban design, are also necessary for the development of related industries, as pointed out by Bakıc1 et al. [8] and Angelidou [41].

Thus, three key factors—-technologies, facilities, and services—should be considered when pushing for a smart city construction project in established cities. Here, technology implies public or private facilities or systems that provide services to citizens; these include related technologies, such as sensing, interface, and network, which have been developed or are under development. The facility category refers to a mechanical device for providing services through technology use. At the same time, from the urban planning perspective, it encompasses structures or urban planning facilities that accommodate those devices and technologies, as well as facilities for the maintenance and development of related industries. As a physical means or as an information good that is provided through technologies, facilities, and devices, a service refers to supplies that citizens can experience and use directly.

Thus, urban planning's physical factors, which aim to regenerate, preserve, and revitalize existing urban spaces and make them "smart," cannot be limited to existing technologies—that is, sensors, networks, and data. Instead, they should include districts or architecture facilities for supporting innovative industries and businesses. In particular, based on the viewpoint that "technology is not enough", smart services should also allow people to think or act "smart" [41].

\section{Materials and Methods}

To implement urban regeneration and smart city projects simultaneously, it is important to choose appropriate technologies that can ensure their continuous use by citizens. In particular, it is necessary to seek ways to boost citizens' satisfaction with the facilities so as to enhance their quality of life in established old cities, given their existing communities, the need to preserve their urban environments, and their limited budgets, among other things.

Each city has its unique social, economic, and financial features, and their business models should differ accordingly. However, smart cities must have consistent and reasonable technologies, facilities, and services (TFS). As such, this research aims to set up a pre-evaluation system for TFS using citizens' points of view and aims to collect experts' opinions and analysis for suggesting implications for the implementation of relevant projects and researches.

\subsection{Research Framework and Model}

With the goal of establishing and evaluating a model for measuring citizens' preference regarding technologies, facilities, and services in a smart city, this study chose related factors that suited old established cities and target sites and carried out a survey. The results were analyzed using a regression model in order to detect factors that affected preferences regarding smart city introduction by highlighting the demographic economy, residents' quality of life, related technologies, facilities, and services. The process of selecting independent variables and the research model and the procedures for collecting experts' opinions were as follows.

First, the demographic, social, and economic features of the respondents were examined. Multiple studies have emphasized that established old cities should be treated using the perspectives of the citizens who reside, work, and perform commercial activities in those spaces, and their demographic, 
social, and economic characteristics are crucial indicators. Accordingly, this study reviewed factors such as gender, age, and income, in a comprehensive manner to suggest implications for local governments and related researchers who may need to supply smart city TFS in a fair manner on a limited budget in the future.

Second, respondents' quality of life was reviewed. Undoubtedly, some indicators can gauge quality of life based on statistics such as housing, economy, employment, life expectancy, suicide rate, and health. However, they are more suited for comparing or evaluating competitiveness between different cities or countries, and they often fail to show the unique features of individuals. Therefore, this study categorized residents' characteristics in terms of residence, health, urban environments, and safety/convenience, and explored them to draw urban planning implications from citizens' perspectives.

Third, this study examined citizens' preferences for each smart city-related technology, facility, and service. Therefore, it analyzed four independent variables related to technology, nine variables related to facility, and eight related to the service sector. South Korean regeneration projects with a focus on revitalizing existing community and urban forms was implemented in the sites considered for this study's review; the following analysis points will be considered:

1. It is necessary to introduce smart city TFS with a greater emphasis on services to minimize changes in urban infrastructures.

2. While implementing smart city projects, public entities should consider the size and budget, the reliability that reflects the maturity and durability of the selected technologies, and their operation and management.

3. Citizens could be indifferent to technologies, facilities, and services other than those they need, and there are criticisms regarding possible budget waste. They could also have low confidence in public entities with regard to various pilot projects, and some could even be skeptical. Considering these points, independent variables in each sector were selected through the following steps.

As mentioned in the literature review, smart city goods were first classified into the following categories: technology, facility, and service (TFS). Next, TFS items, which were either already introduced or yet to be introduced, were selected based upon [42-46] along with documents by related governments, which listed domestic smart city TFS projects based on [47]. They were then narrowed down to select smart city construction projects led by public entities for existing old cities. As a next step, 12 individuals, including experts, government officials, researchers, and representatives for local residents, conducted focus group interviews (FGI) and reviewed the items based on the following criteria: whether they could be implemented in the target areas within the project period, whether their technologies were mature enough, whether related data could be properly managed and maintained, and whether the items could be managed in a sustainable manner after being installed. Here, the fact that smart city services can be realized through related technologies and that they can involve structures or urban planning facilities was considered. Technologies and services were chosen through discussions conducted mainly with citizens, but the facilities subject to the research were selected by smart city experts and public officials in the urban planning field. The facilities are designed to function as control/data centers and administrative offices that deal with services and technologies, and those that help to boost the sustainability of smart cities (e.g., industrial facilities and education centers).

Through the aforementioned process, 5 items were finally selected in 4 fields in the "technology" category, 12 items out of 5 fields in "facility," and 12 items out of 5 fields in "service." In order to minimize any possible differences between opinions of citizens, experts, and public entities regarding the research course, this research assigned weighting to each variable based on experts' evaluation; this was determined through two rounds of the Analytic Hierarchy Processes (AHPs). Based on the results of the weight value and responses to a pilot survey, the survey variables were finally fixed; its contents and results are shown in Figure 1 and Table 1. 


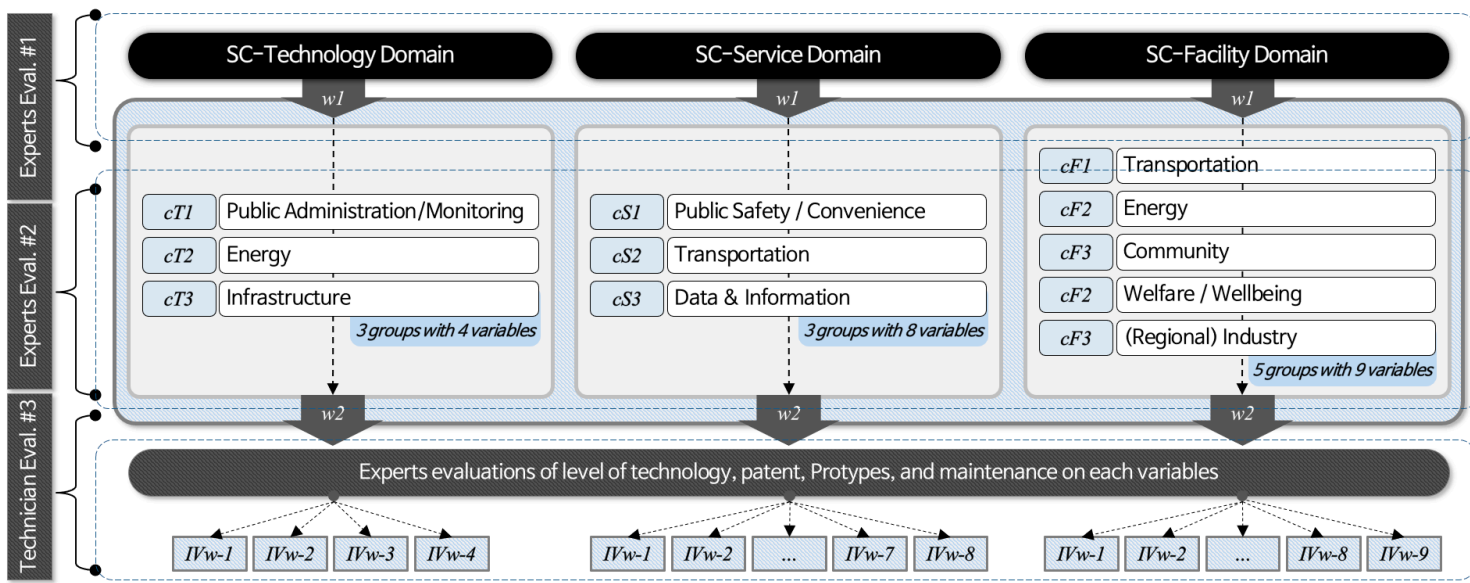

Figure 1. Technology, Service and Facility domains and weights of each variable used for AHP analysis.

Table 1. Independent (I.V.) variables of Research Model III and dependent variable (D.V.).

\begin{tabular}{|c|c|c|c|}
\hline $\begin{array}{c}\text { Class } \\
\text { (w1, Rank) }\end{array}$ & $\begin{array}{l}\text { Variable Group } \\
\text { (w2, Rank) }\end{array}$ & Evaluation Criteria (w3, Rank) & Scales \\
\hline $\begin{array}{c}\text { Technology (TEC) } \\
(0.276,3)\end{array}$ & $\begin{array}{l}\text { Public Administration/ } \\
\text { Monitoring } \\
(0.325,2) \\
\text { Energy } \\
(0.115,3) \\
\text { Infrastructure }(0.411,1)\end{array}$ & $\begin{array}{c}\text { E-administrative process complaint handling } \\
(0.081,4) \\
\text { Real-time city monitoring by a control center } \\
(0.090,3) \\
\text { Energy provision, control, management } \\
\text { technology for stable energy provision }(0.029,2) \\
\text { Sensor-based infrastructure and facility } \\
\text { monitoring }(0.113,1)\end{array}$ & $\begin{array}{c}\text { Likert } 11 \text { points } \\
(0=\text { highly disfavored } \\
10=\text { highly preferred })\end{array}$ \\
\hline $\begin{array}{l}\text { Service (SVC) } \\
(0.399,1)\end{array}$ & $\begin{array}{l}\text { Public Safety } \\
\text { /Convenience } \\
\quad(0.271,2) \\
\text { Transportation } \\
\quad(0.231,3)\end{array}$ & $\begin{array}{c}\text { Safety and disappearance monitoring for women, } \\
\text { the elderly, and children }(0.101,6) \\
\text { Real-time monitoring of illegal parking, fire and } \\
\text { crime detects and controls }(0.105,5) \\
\text { Introduction of eco-friendly and intelligent } \\
\text { transportation }(0.092,7) \\
\text { Real-time information of public transportation } \\
\text { arrivals and parking lots }(0.092,7) \\
\text { Single or ambi-directional digital signage and } \\
\text { kiosk }(0.157,1) \\
\text { Provision of local community information and } \\
\text { data by web or API }(0.152,3) \\
\text { Public wireless access point }(0.157,1) \\
\text { Privatized real-time city monitoring by personal } \\
\text { device }(0.142,4)\end{array}$ & $\begin{array}{c}\text { Likert } 11 \text { points } \\
(0=\text { highly disfavored } \\
10=\text { highly preferred })\end{array}$ \\
\hline $\begin{array}{c}\text { Facility (FAC) } \\
(0.325,2)\end{array}$ & $\begin{array}{c}\text { Energy } \\
(0.231,3) \\
\text { Community } \\
(0.127,4) \\
\text { Welfare/Wellbeing } \\
(0.113,5) \\
\\
\text { Local } \\
\text { Industry } \\
(0.212,2)\end{array}$ & $\begin{array}{c}\text { Smart traffic (lights) control and automated } \\
\text { shade on crosswalk and station }(0.080,1) \\
\text { EV (electric)/HFCV (Hydrogen fuel cell) charging } \\
\text { station }(0.077,2) \\
\text { Smart street poll, and smart street bin }(0.077,2) \\
\text { Energy production, management center (or } \\
\text { facility) for prosumer }(0.047,5) \\
\text { Community hall (or community service center) } \\
(0.041,6) \\
\text { Culture center, (leisure) sports center }(0.037,7) \\
\text { Daily care center for the senior and disabled } \\
\text { (0.037, } 7) \\
\text { Tourist information center (or tourism supportive } \\
\text { facilities) }(0.069,4) \\
\text { Local strategic or knowledge industrial complex, } \\
\text { town, or building }(0.069,4)\end{array}$ & $\begin{array}{c}\text { Likert } 11 \text { points } \\
(0=\text { highly disfavored } \\
10=\text { highly preferred })\end{array}$ \\
\hline D.V. & $\begin{array}{l}\text { Preference on Smart City } \\
\text { Project in site }\end{array}$ & $\begin{array}{c}\text { Overall preference to smart city project on local } \\
\text { area of a respondent }\end{array}$ & \\
\hline
\end{tabular}

The details are as follows:

1. The first AHP was conducted to evaluate the importance of smart city technologies, facilities, and services so as to figure out the importance of key elements for smart city projects in existing old cities (See Figure 1-w1). 
2. The second AHP was conducted to evaluate the importance of the variables included in the three categories. By doing this, rankings were drawn for variable groups included in the technology (3), facility (3), and service (4) categories (See Figure 1-w2). The weighting value of each variable group was calculated after being multiplied by the result of the first AHP process.

Across processes 1 and 2, the AHPs were carried out with the aid of nine smart city experts (fields: solution and R\&D; average career: 10.3 years), seven urban planning and electronics experts (fields: smart city; average career: 11.4 years), and five officials from related public institutions and public firms (fields: smart city and related legal systems; average career: 13.1 years). The results were derived from 19 questionnaires after eliminating 2, which showed the consistency ratio (C.R.) of 0.1 or higher. Here, the AHP is a pairwise comparison matrix, which means two unique values configure the eigenvector in order to calculate the weight and the comparative importance of the upper structure based on evaluation and integration of sub elements.

For the evaluation of the eigenvalue, which serves as the decision-making standard, the paired comparison scale of 9 points by Saaty [48] was used. This scale compares the importance of one main evaluation criterion with that of another: when they are equally important, the value reaches 1 . When one of these two criteria shows a clear comparative advantage, the value grows to 3, 5, 7, and finally 9. The following decision matrix has been established based upon those contents and calculation method (Equation (1)):

$$
A=\left[\begin{array}{ccccc}
a_{11} & a_{12} & a_{13} & \cdots & a_{1 n} \\
a_{21} & a_{22} & a_{23} & \cdots & a_{2 n} \\
\cdots & \cdots & \cdots & \cdots & \vdots \\
a_{n 1} & a_{n 2} & a_{n 3} & \cdots & a_{n n}
\end{array}\right] B=\left[\begin{array}{ccccc}
b_{11} & b_{12} & b_{13} & \cdots & b_{1 n} \\
b_{21} & b_{22} & b_{23} & \cdots & b_{2 n} \\
\cdots & \cdots & \cdots & \cdots & \vdots \\
b_{n 1} & b_{n 2} & b_{n 3} & \cdots & b_{n n}
\end{array}\right]
$$

where, $i$ and $j$ vary from 1 to $n$. In Matrix $\mathrm{A} a_{i j}=1, a_{i j}=1 / a_{i j}$ for $i \neq j$. The importance of each item $\left(\omega_{i}\right)$ in Matrix B is calculated as follows (Equation (2)):

$$
b_{i j}=\frac{a_{i j}}{\sum_{n=1}^{n} a_{i j}}, \omega_{i}=\frac{1}{n} \sum_{j=1}^{n} b_{i j}
$$

Last, the constancy index in pairwise comparison matrices is calculated as follows (Equation (3)):

$$
\lambda_{\max }=\sum_{j=1}^{n}\left\{\sum_{i=1}^{n} a_{i j} \cdot \omega_{i}\right\}, \mathrm{CI}=\frac{\lambda_{\max }-n}{n-1}
$$

The weighting for each variable group is obtained again based on the previously calculated value. This process was conducted through a focus group interview with nine experts and researchers who had good knowledge about the related projects, as this research has considered the implementation of a regeneration project in existing old cities and the simultaneous installation of smart infrastructures. In four levels from $0 \%$ (very good), to $-3.3 \%,-6.6 \%$, and $-10 \%$ (neutral or bad), each variable was evaluated in terms of patent, prototype, commercialization, maintenance and management, and expansion potential. The results were then applied to independent variables to draw the final weighting (see Figure 1-w3). Last, independent variables for the survey were selected, as shown in Table 1. After deleting or integrating items that were deemed redundant or confusing, four indicators were selected from three fields in "technology," eight indicators from three fields in "service," and nine variables from four groups in "facility." Next, each content was rewritten using citizens' points of view; this exercise aimed to help the citizens better understand the questionnaires.

As for independent variables selected from the categories of technology, service, and facility, technology includes public-led electronic administrative process, control technology, and energy management, most of which have been introduced in the researched sites. To boost respondents' understanding, the technology items were written with a focus on their service features. The service 
category included public safety and convenience, transportation, and data and guidance; its items included urban safety, real-time monitoring in environmental fields, the provision of living information and public information centered on websites as well as the application programming interface (API), wireless AP, and one-way and two-way kiosks. Most of the items are already available and operating in some counties. Facility is related to traffic, energy, community, welfare, and local industries, which are mostly accompanied by architectural and urban planning facilities. In particular, items such as industrial complexes consider the characteristics of urban regeneration projects in local economic revitalization.

As mentioned above, this study aimed to conduct a regression analysis based on respondents' socio-economic features, quality of life (Table 2), preferred items from among the technologies, facilities, and services of a smart city (as independent variables), and degree of smart city infrastructure introduction in the survey areas (as the dependent variable). For this process, this study adopted the Hierarchical Regression Analysis (HRA), which introduces independent variable groups into the regression model in phases. This helps to confirm what factors affect preferences regarding smart cities and the strength of their impact.

Table 2. The other independent (I.V.) variables of Research Model I and II.

\begin{tabular}{|c|c|c|c|}
\hline Class & Variable Group & Evaluation Criteria (w3) & Scales \\
\hline \multirow{3}{*}{$\begin{array}{l}\text { Socio-Economic } \\
\text { Characteristics }\end{array}$} & Gender & Man (1), Woman (0) & Dichotomous \\
\hline & Age & Age (squared value) & Open \\
\hline & Salary & $\begin{array}{c}\text { Average salary per household (5 intervals, from } \\
\text { approx. } 1250 \text { USD to } 4166 \text { USD) }\end{array}$ & Selective \\
\hline \multirow{5}{*}{$\begin{array}{l}\text { Quality of Life } \\
\qquad \text { (QoL) }\end{array}$} & Housing & $\begin{array}{l}\text { Subjective satisfaction of housing } \\
\text { facilities and environment }\end{array}$ & \multirow{5}{*}{$\begin{array}{c}\text { Likert } 11 \text { points } \\
(0=\text { highly unsatisfied } \\
10=\text { highly satisfied }\end{array}$} \\
\hline & Urban & Subjective satisfaction of overall & \\
\hline & Environment & urban environment & \\
\hline & Health/Wellbeing & $\begin{array}{l}\text { Subjective satisfaction of current physical } \\
\text { and mental health }\end{array}$ & \\
\hline & Safety/Convenience & $\begin{array}{l}\text { Subjective satisfaction of safety of } \\
\text { surrounding area }\end{array}$ & \\
\hline
\end{tabular}

The methodology is based on the hypothesis that respondents' individual characteristics, personal backgrounds, and experiences with similar facilities affect their level of preference regarding goods that are to be introduced in the future, and that those factors also affect the dependent variable in the regression model. Regarding actual related research areas, Baptiste, A.K., et al. [49] used demographic-social indicators in a regression model in policy evaluation, which considers public participation; furthermore, Maas and Hox [50] and Willms [51] emphasized the requirement for demographic-social characteristics to be placed first, superseding any other independent variables, while citing the hierarchy of each independent variable in similar regression models (see Figure 2).

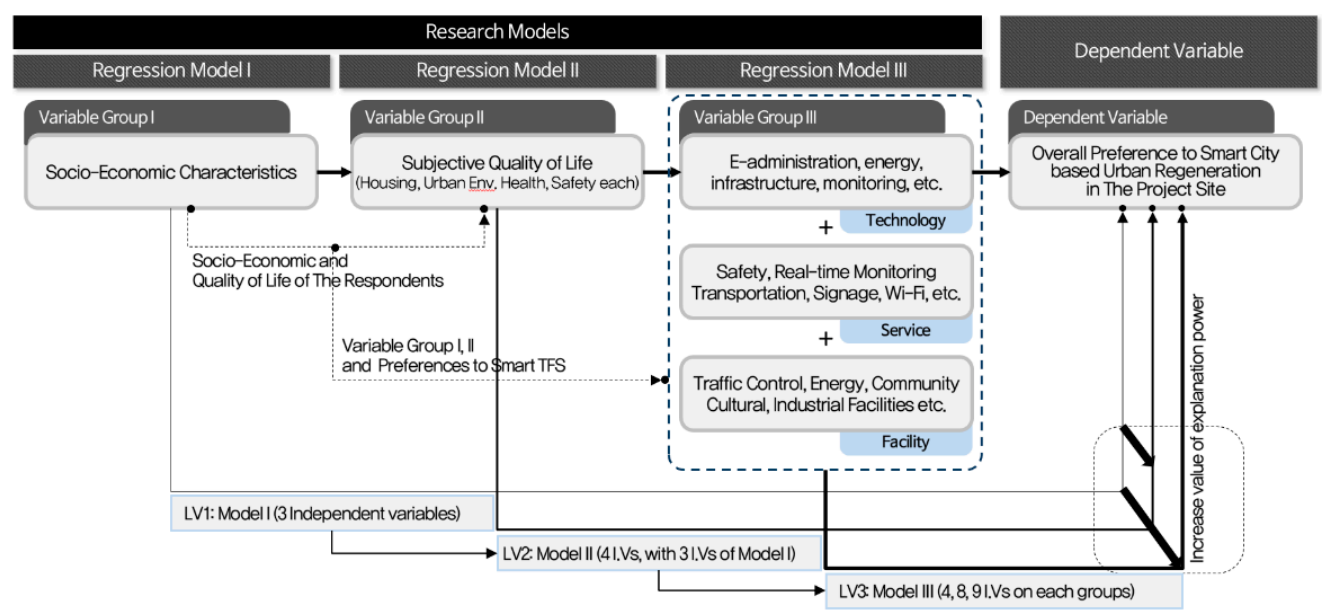

Figure 2. Hierarchical Regression Model (HRA) of this research. 
From the same perspective, this study put (1) demographic and social status variables, such as gender, age, and income mentioned in the Table 2 to regression model I. Then (2) the subjective quality of life that each individual evaluates currently was applied to regression model II, and (3) the two abovementioned factors along with each smart city's TFS were applied to regression model III; this is expected to show the highest explanatory power. In other words, HRA can be considered as a model that indicates which TFS should be introduced first, which can contribute to the improvement of citizens' quality of life, and what problems can obstruct the introduction of a smart city.

\subsection{Study Areas and Data Collection}

For the abovementioned purposes, this study selected target sites where a smart city project is being planned in accordance with related laws and regulations; next, a survey of residents was conducted to explore desirable ways to achieve a smart city that meets citizens' needs.

To choose project sites, first, a total of eight places were selected: five sites were among 68 places picked by [52] in 2017 as candidates for the regeneration project of old existing cities; two were where smart city-related living labs and the introduction of ICT technologies were highlighted; and one was a site where a smart city establishment project led by public companies is being planned. Second, after in-depth discussions with experts and public officials, five out of the eight areas were selected; these bore similarities in terms of project size, budget, and duration. Finally, three areas were chosen by eliminating two metropolitan areas in order to focus on old cities in provincial areas. Since December 2018 - when the central government announced a smart regeneration project-many discussions have been held regarding the types of technologies and services that will be introduced in the three cities, and local governments have collected public opinions regarding the matter. Then, in 2019, information network systems began to be expanded or newly installed in the three regions to introduce the necessary infrastructure for smart city construction. Therefore, analysis of samples from the cities is expected to show residents' recognition of and preference for a smart city project in existing old cities. The three cities show differences in location, urban environments, and related policy measures. Through the comparison of their analysis results, this research is expected to present implications for future researches on cities with similar physical and social conditions. The status and plans of each target site as of 2019 were as follows:

The Jochiwon project aims to improve living environments in old downtown areas, revitalize their major commercial zones, and attract companies to them for job creation. In detail, local and central governments are considering the construction of control centers, electronic libraries, and living lab spaces for creating user-friendly smart city infrastructures [47]. The Pohang project called for the introduction of a comprehensive platform that involves smart city technologies. It also aims to introduce Internet of Things (IoT) in transportation, environment, and energy sectors as well as Artificial Intelligence-based information and communication technologies. Through such smart city projects, the government seeks to boost the security and safety of citizens and to improve their responses to natural disasters. Related facilities and services are to be introduced in existing centers for public affairs, businesses, and culture [47]. In Cheonan, the project aims to help the city specialize in crime prevention, disaster management, and effective energy usage by integrating its related platforms with those of neighboring cities. The city has also been gathering residents' opinions about envisioned programs such as the introduction of eco-friendly transportation and real-time traffic notification systems (see Figure 3) [47]. 


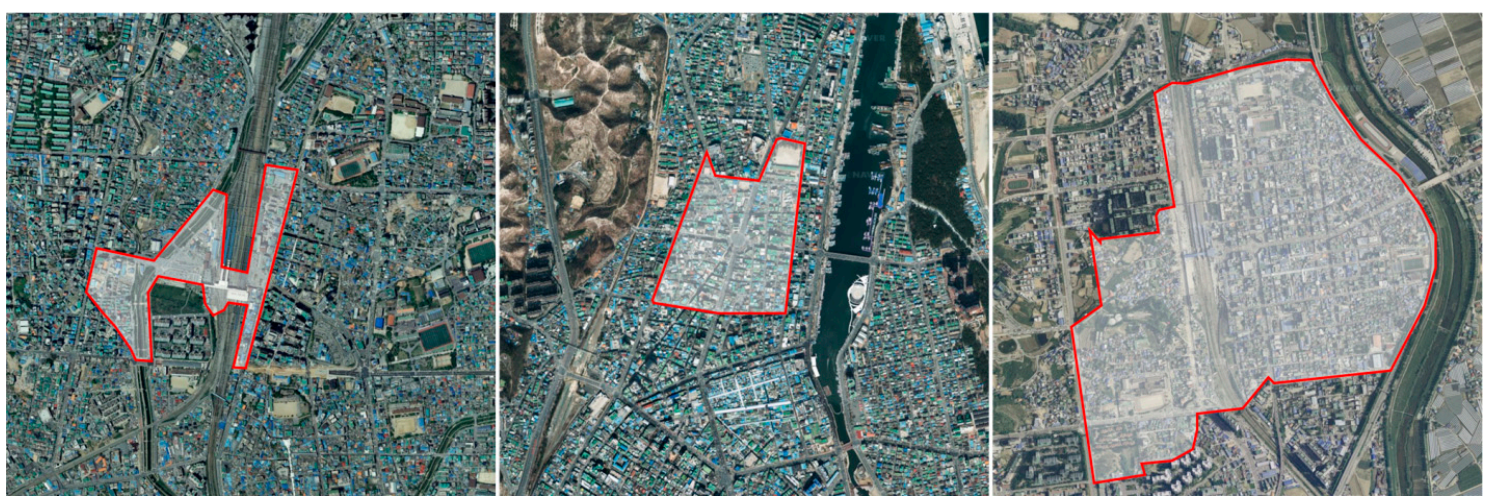

Figure 3. Research sites (left: Jochiwon, middle: Pohang, right: Cheonan*; *: Specific site(s) for project is under discussion by the public sector, Images source from https://map.naver.com).

Considering the project scale and walking distances, the survey's spatial scope was limited to a radius of $500 \mathrm{~m}$. To expand the result implications, geographic information system (GIS) was used to learn about and present land use plans, the age of the structures, and other details of government-led projects. The survey sample was limited to those aged between 20 and 65 years, and the selected participants lived in the target area or adjacent districts for more than three years and had experiences of using business and commercial facilities. The sample was extracted through stratified random sampling based on age, and the minimum administrative district for collecting demographic statistics was set as the research population. The number of residents in the research sites and the results of the population calculation were as follows, and the sampling error was calculated using the following Equation (4).

$$
\begin{gathered}
\mathrm{n}=\frac{\mathrm{z}_{\mathrm{a}}^{2} \times \mathrm{p}(1-\mathrm{p})}{\mathrm{e}^{2}} \\
\mathrm{e}=\mathrm{Z}_{\frac{\mathrm{a}}{2}} \times \sqrt{\frac{\mathrm{p}(1-\mathrm{p})}{\mathrm{n}}}
\end{gathered}
$$

where $\mathrm{n}$ is numbers of respondents, $\mathrm{e}$ is margin of error of confidence interval, $\mathrm{z}$ is confidence level $(95 \%,=1.96)$, and $\mathrm{p}$ is the observed percentage $(p=0.5)$.

In order to review the validity of each survey and to check respondents' understanding, a pilot survey was first conducted involving 39 people in Jochiwon and 44 in Cheonan. Next, the questionnaire was reviewed with the aid of public officials and local activists with a focus on such details as explanations of smart city TFS. Then, the sample survey was conducted: 211 people in Jochiwon (population of 31,496, 95\% CI, SE $=6.92 \%$ ); 201 people in Cheonan (population 79,245, 95\% CI, $\mathrm{SE}= \pm 6.9 \%$ ); and 231 people in Pohang (population 51,579, 95\% CI, SE $=6.43 \%$ ). The respondents of the three cities $(n=624)$ and their demographic, social, and economic features are as follows (see Table 3).

In January 2019, a pilot survey was conducted involving 39 and 44 people in Jochiwon and Cheonan, respectively; this was followed by the first main survey between March and May. Next, in Pohang, a survey was conducted from April through July. All the surveys were administered face to face by pollsters who majored in urban planning or information technology and received education on this subject. The response rates reached $43.5 \%$ in Jochiwon, 39.7\% in Pohang, and 47.0\% in Cheonan. 
Table 3. Socio-economic characteristics of respondents $(n=624)$.

\begin{tabular}{|c|c|c|c|c|}
\hline \multicolumn{2}{|c|}{ Classification and Criteria } & $\begin{array}{c}\text { Jochiwon } \\
\text { (n = 208/31,496) }\end{array}$ & $\begin{array}{c}\text { Pohang } \\
(n=200 / 51,579)\end{array}$ & $\begin{array}{c}\text { Cheonan } \\
(n=216 / 79,245)\end{array}$ \\
\hline \multirow{3}{*}{ Gender } & Male & $105(52.5 \%)$ & $107(50.71 \%)$ & $113(52.31 \%)$ \\
\hline & Female & $95(47.5 \%)$ & $104(49.29 \%)$ & $83(47.69 \%)$ \\
\hline & Sum & $208(100 \%)$ & $200(100 \%)$ & $216(100 \%)$ \\
\hline \multirow{6}{*}{ Age Group } & $20-29$ & $35(17.5 \%)$ & $26(22.1 \%)$ & $52(24.1 \%)$ \\
\hline & $30-39$ & $30(14.8 \%)$ & $51(19.7 \%)$ & $46(21.4 \%)$ \\
\hline & $40-49$ & $42(21.0 \%)$ & $51(24.3 \%)$ & $46(21.0 \%)$ \\
\hline & $50-59$ & $57(28.7 \%)$ & $50(24.0 \%)$ & $51(24.1 \%)$ \\
\hline & $60-65$ & $36(18.1 \%)$ & $21(10.0 \%)$ & $19(8.9 \%)$ \\
\hline & Sum & $208(100 \%)$ & $200(100 \%)$ & $216(100 \%)$ \\
\hline \multirow{7}{*}{ Income Level } & Under 1250 USD & $24(12.00 \%)$ & $28(13.46 \%)$ & $32(14.81 \%)$ \\
\hline & 1250-2083 USD & $38(19.00 \%)$ & $41(19.71 \%)$ & $42(19.44 \%)$ \\
\hline & 2083-2500 USD & $55(27.50 \%)$ & $63(30.29 \%)$ & $64(29.63 \%)$ \\
\hline & 2500-3333 USD & $45(22.50 \%)$ & $43(20.67 \%)$ & $42(19.44 \%)$ \\
\hline & 3333-4167 USD & $29(14.50 \%)$ & $31(15.00 \%)$ & $32(15.00 \%)$ \\
\hline & Over 4166 USD & $9(4.50 \%)$ & $2(2.88 \%)$ & $4(1.85 \%)$ \\
\hline & Sum & $208(100 \%)$ & $200(100 \%)$ & $216(100 \%)$ \\
\hline \multirow{10}{*}{ Occupation } & Regular & $101(50.50 \%)$ & $80(38.46 \%)$ & $91(42.13 \%)$ \\
\hline & Non-regular & $25(12.50 \%)$ & $59(28.37 \%)$ & $54(25.00 \%)$ \\
\hline & Unemployed & $74(37.00 \%)$ & $69(33.17 \%)$ & $71(32.87 \%)$ \\
\hline & Administrative & $8(4.00 \%)$ & $9(4.33 \%)$ & $16(7.41 \%)$ \\
\hline & Professional & $8(4.50 \%)$ & $6(2.88 \%)$ & $5(2.31 \%)$ \\
\hline & White-collar & $29(14.50 \%)$ & $23(11.06 \%)$ & $17(7.87 \%)$ \\
\hline & Sales/Service & $45(22.50 \%)$ & $25(12.02 \%)$ & $43(19.91 \%)$ \\
\hline & Farmer/Fisher & $11(5.50 \%)$ & $55(26.44 \%)$ & $39(18.06 \%)$ \\
\hline & Student, etc. & $98(49.00 \%)$ & $90(43.17 \%)$ & $96(44.45 \%)$ \\
\hline & Sum & $208(100 \%)$ & $200(100 \%)$ & $216(100 \%)$ \\
\hline \multirow{5}{*}{$\begin{array}{l}\text { The Number of } \\
\text { Residents } \\
\text { in a Household }\end{array}$} & 1 & $31(15.50 \%)$ & $25(12.02 \%)$ & $39(18.06 \%)$ \\
\hline & 2 & $61(30.50 \%)$ & $74(35.58 \%)$ & $72(33.33 \%)$ \\
\hline & 3 & $72(36.00 \%)$ & $73(35.10 \%)$ & $78(36.11 \%)$ \\
\hline & Over 4 & $36(18.00 \%)$ & $35(17.31 \%)$ & $27(12.50 \%)$ \\
\hline & Sum & $208(100 \%)$ & $200(100 \%)$ & $216(100 \%)$ \\
\hline
\end{tabular}

\section{Results}

\subsection{Overview}

This research's literature review emphasized the importance of collecting opinions from citizens, when pushing for the simultaneous introduction of projects for urban regeneration and smart city infrastructures, especially when there are limitations in budget and other physical factors. As such, it sorted out appropriate technologies, facilities, and services (TFS) for launching a smart city project at three similar sites; it then measured citizens' demographic characteristics and their objective and subjective quality of life in order to introduce subjective factors in the statistical model and thus, examine factors that affect citizens' preference regarding smart cities. In the main part of results, the survey results regarding independent variables were reviewed first, and diverse information, including each city's aging level and land use, were presented over its course in order to produce results that reflected citizens' opinions and local circumstances.

The number of respondents was 208 in Jochiwon, 216 in Cheonan, and 200 in Pohang city, and all the three sites satisfied the sample error of $\pm 6 \%$ with a confidence interval of $95 \%$ based on the population. The three cities - all in provincial regions-are old and have been designated by the central government as sites for urban regeneration projects that aim to revitalize areas in old cities and thus, boost their social and physical vitality [53]. Currently, smart city technology screening and related infrastructures, including data centers, are being installed in these areas, and the local governments have been launching PR efforts while collecting residents' opinions on smart city projects. 
The three cities are similar in that they all have several old and low-rise buildings that were built more than 30 years ago (as shown in Figure 4), but some differences were spotted in their actual land use, their current status, and urban regeneration plans.

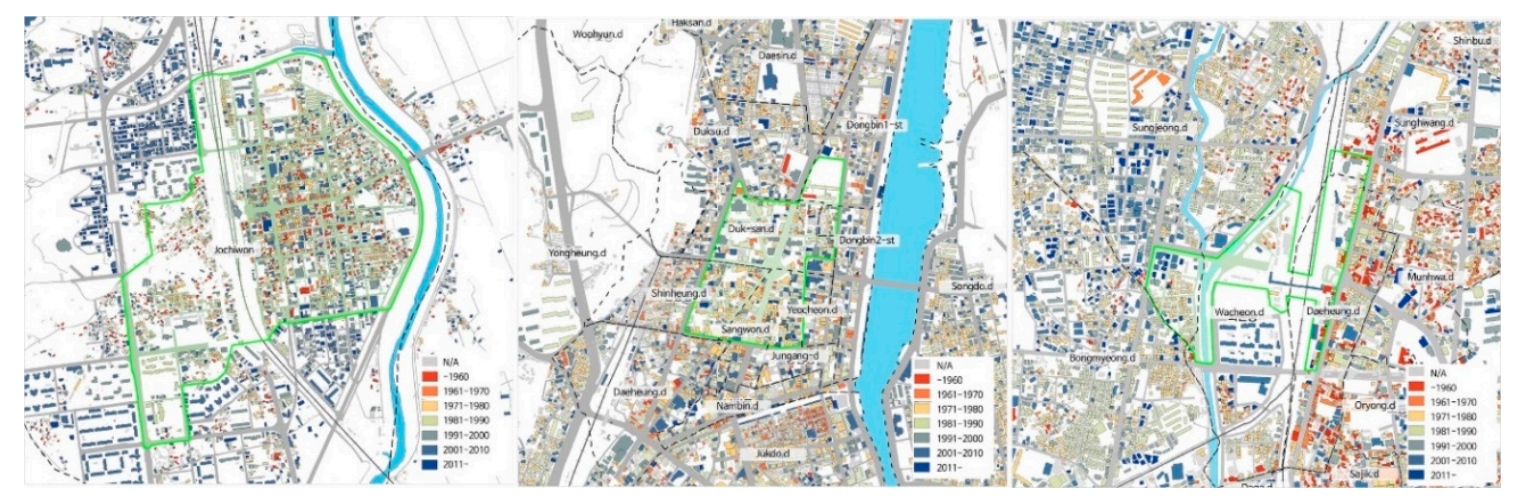

Figure 4. The age of buildings in research sites (left: Jochiwon, middle: Pohang, right: Cheonan).

Considering the business plans of each city, Jochiwon aims to establish governance that is presented directly by citizens; the goal is to revitalize the transportation and industry fields in a smart fashion based on participation by private and public entities as well as universities. As for its physical circumstances, the metropolitan railway station is located at the center of the project site. Across the project site, the semi-residential zone, which accommodates both commercial and residential facilities, accounts for the largest share: $16.28 \%$. Within the area of a $500 \mathrm{~m}$ radius, however, the general residential area takes up the largest section (excluding green areas): $31 \%$. Therefore, the site shows a mixture of transportation, commerce, and housing functions.

Pohang has faced some decline, as its city center was changed. Therefore, the local government, along with public firms, aims to build a smart city by introducing information and communication technologies in its central part. This city is also attempting to establish an industry center for young entrepreneurs and to redevelop old housing areas so as to attract more visitors and tourists. In opposition to Jochiwon, the general residential area accounted for about $42.8 \%$ of the total area in Pohang. Within its surveyed range, the ratio of commercial area $(32.5 \%)$ was higher than that of general residential area $(25.38 \%)$, which is a typical feature of a declining local city center.

As in Jochiwon, Cheonan's metropolitan railway station is also located at the center of the target area, but it had declined due to the formation of a new city center, as was the case in Pohang. It has good accessibility to the capital city, thanks to the metropolitan railway, but the very existence has accelerated the city's decline. Accordingly, the government aims to create a dynamic and competitive city by introducing projects to create innovative districts around the station, preserve residential areas, and install smart city infrastructures. Commercial districts accounted for around $30.77 \%$ of the total target zone in Cheonan. Within a radius of $500 \mathrm{~m}$, however, the general residential area $(32.5 \%)$ is bigger than the commercial zone $(25.38 \%)$, thus indicating that commercial areas are quite densely formed.

\subsection{Quality of Life and Preference for Smart City TFS}

As highlighted in this research's literature review, respondents' quality of life was the most important factor for implementing urban regeneration projects in old established cities. The survey results showed that quality of life in all three cities was scored 4.95 to 5.07 out of 10, which was similar to or slightly lower than the national average of 5.39 indicated by the survey of [48]. The comparison of quality of life among the three areas showed that they were similar because level of health scored the lowest, while residential and urban environments had relatively high figures. In Pohang, satisfaction level regarding safety received lower scores compared to other cities, though it houses relatively recently built buildings compared to other cities. Interviews with citizens attributed this result to multiple earthquakes that had hit the city the previous year. 
More than $60 \%$ of the respondents said that they were aware of the smart city concept, and the main sources of their recognition included PR campaigns by public entities and media. In addition, respondents had used electronic petitions, public bicycles, public transportation guidance, disaster notification messages, display boards, parking lot guides, and free Wi-Fi through personal or public terminals, and about $42 \%$ said they were satisfied with those services.

Respondents' preferences for each smart city technology, facility, and service item are indicated in Figure 5 (from 2 to 4 ), and some similarities were spotted among these sites.

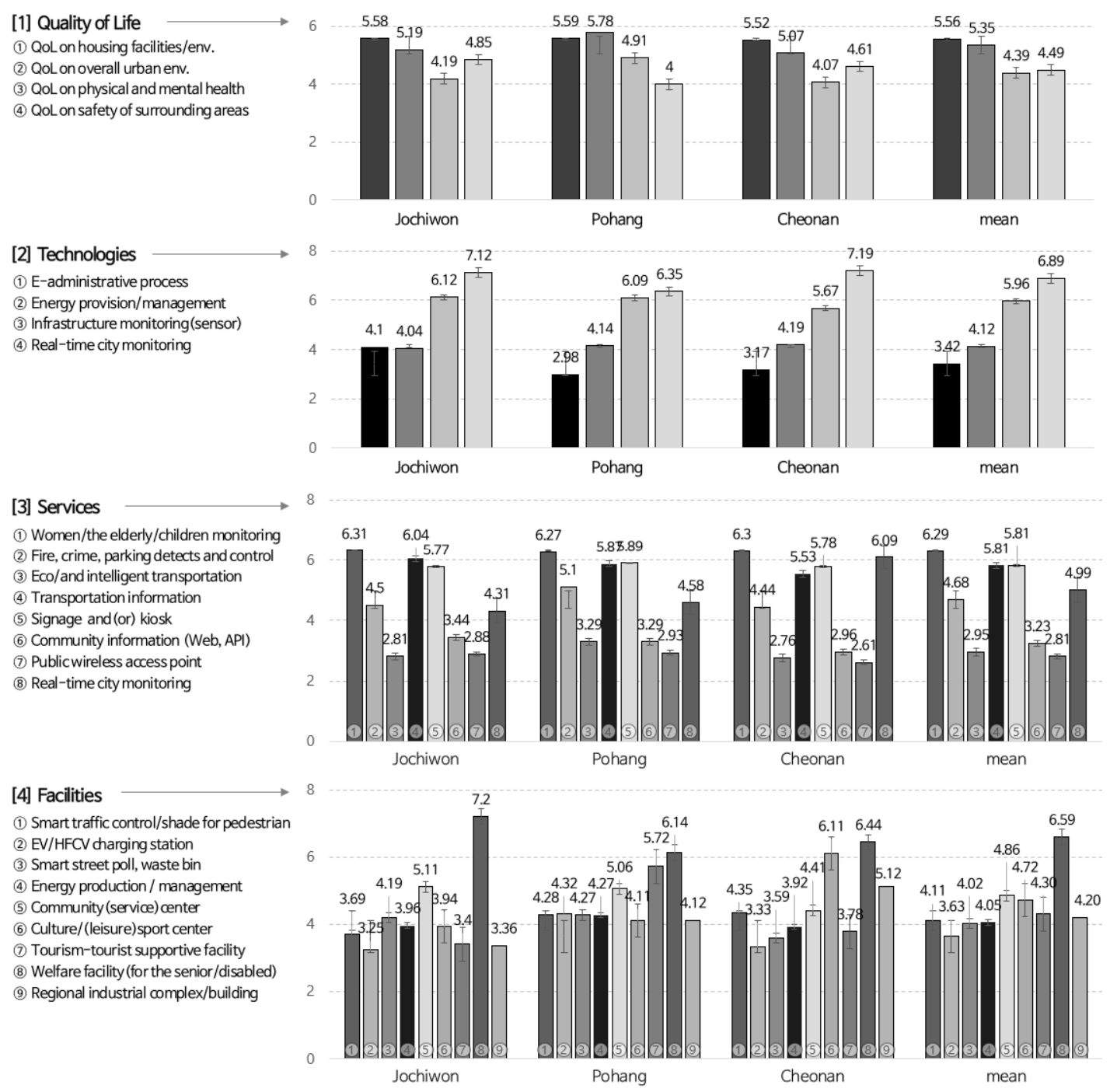

Figure 5. Results of QoL (Quality of Life) and preferences for each of the Technology, Facility, and Service variables.

The results showed that, in general, citizens showed high interests in collecting and processing various local information about fires, accidents, and crimes. Their demands were centered on the improvement of overall living conditions, such as the monitoring of and crackdown on illegal waste dumping and illegal parking. On the other hand, there were relatively low calls for introducing technologies for the electronic processing of public complaints in government agencies, which have already been widely distributed and well implemented, and energy-related strategies whose services had not yet been decided.

Each city showed some differences in preferences for smart city-related services. Overall, however, the preference level was higher for monitoring and related services for the safety of women, the elderly, 
and children (6.29), fire/crime/illegal parking control service (5.87), and public transportation arrival notification and parking lot information (5.86), thus indicating that citizens are generally interested in services related to everyday safety and convenience.

Furthermore, preference for public Wi-Fi (4.58), which involves relatively low technology, was quite high. As for projects involving kiosks and electric signboards (with an average of 3.29), however, respondents showed a low preference in general, and projects such as the introduction of public bicycles, autonomous vehicles, and shared vehicles (3.29 on average) turned out to be less popular. Web- or application-based urban living information services (2.93 on average), which have been pushed for by local governments since 2010, earned the lowest scores. Respondents said the amount of information available was already sufficient.

Figure 5 shows the results of introducing structures and facilities to realize smart city technologies and services, and to foster related industries and education. The average preferences for medical facilities and facilities for the elderly and the disabled (6.57) were the highest, followed by residents' welfare and community facilities (4.86), and cultural and sporting facilities (4.78). The preferred facilities differed based on the current circumstances of each district, but interest in energy (4.05) and electric/hydrogen cell vehicle (4.02) was found to be relatively low despite central and local governments' initiatives and subsidies for their popularization.

There were also differences in respondents' preferred facilities based on the current status of each region. In Pohang, where the need to attract tourists was highlighted, residents' preference for building tourism support facilities was lower than that of other cities' residents. Energy and electric vehicle/hydrogen battery facilities also received a relatively poor evaluation in the three regions, though the project is pushed for by their governments. Such cases indicate that there could be a gap in policy goals and directions between public and private entities.

\subsection{Regression Model Results}

According to the survey, the preference levels for smart city technologies, facilities, and services did not reveal significant disparities between the cities. In the case of some construction and urban planning facilities, significant differences were spotted according to their related infrastructure. Such evaluations, however, simply reflect arithmetical figures in respondents' responses, and this presents limitations for grasping the overall tendency of respondents who want a smart city. Therefore, this study tried to examine what elements could affect overall preference levels regarding the introduction of smart city TFS based on citizens' points of view; the aim was to present results that can be used for follow-up researches and related projects as well as technology development. Analysis through the application of the HRA model to survey results was as follows (see Table 4).

First, both the overall results of the three cities' samples, which were included in the research model, and the individual results of each city were found to be significant. The suitability and the explanatory power of the model could be assessed through changes in $\mathrm{R}$ value during each step of the HRA. When the independent variable groups were included in the regression model—one after the other-the explanatory power grew during each step to describe the dependent variable. In other words, based on the R2 value calculated after including all samples, this model explained $16.3 \%$ of dependent variables in terms of citizens' social and economic features. As independent variables regarding quality of life were included, the explanatory power of the model rose by $12.3 \%$ to stand at $28.6 \%$.

When smart city TFS was applied to Model 3, the explanation power surged from $34.2 \%$ to $62.8 \%$, thus indicating that respondents' current status, their quality of life, and their overall preference regarding smart city projects which accurately explained their overall preference for smart city projects. 
Table 4. Results of HRA models of the three research sites $(n=624)$.

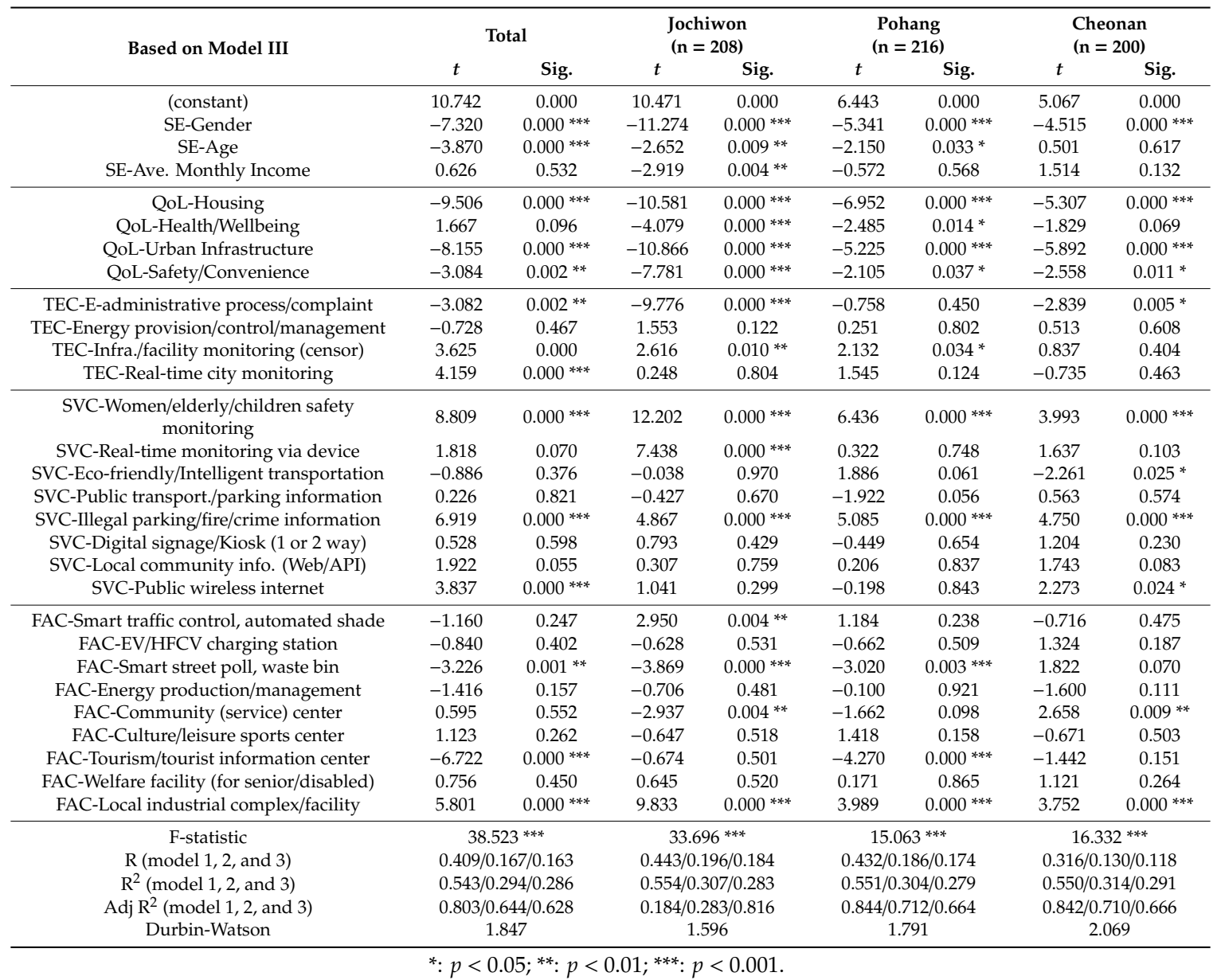

Considering independent variables that affect dependent variables in terms of the aggregate values of all three cities' samples, male citizens and younger people contributed to the increase in overall preference levels for smart city projects. However, residents' income did not affect the results. Regarding quality of life, lower satisfaction levels with housing, urban circumstances, infrastructures, and safety-related circumstances led to a greater impact on the dependent variable's explanatory power. This could be interpreted to indicate that they perceived smart city projects as a positive means of improving adverse environments for their current business, residential, and commercial activities. As such, citizens' quality of life can be said to have negative correlations with the dependent variable, but their preference for individual smart city technologies, facilities, and services has either a positive or negative effect on the dependent variable. According to $t$-value, control and management services related to the safety of women, the elderly, and children could have the strongest effect on preference levels for smart city businesses, followed by monitoring of and crackdown on fire, crime, and illegal parking $(t=6.919, p=0.000)$ and the creation of knowledge industry complexes $(t=5.801, p=0.000)$. Control of and crackdown on waste disposal and illegal parking $(t=4.159, p=0.000)$ and public Wi-Fi $(t=3.837, p=0.000)$ also contributed to the higher level of preference. On the other hand, smart street lamps and trash cans $(t=-3.226, p=0.001)$, which have been introduced by many countries and cities, and tourism support centers and related promotion facilities $(t=-6.722, p=0.000)$ showed a negative correlation with the dependent variable. In terms of the research model, the Durbin-Watson (D-W) test value for assessing the independence of observation was 1.847, which is close to 2 . As the value did not approach either 0 or 4 , and little auto correlation was found, the result can be considered valid.

Thus, the results indicate that citizens perceive smart cities as a means of improving their safety, convenience, and their local environments. It is in this context that smart city projects are advised 
for highlighting the supply of necessary facilities and infrastructures, and for improving residents' living circumstances in established old cities, as is the case in traditional urban regeneration projects. Therefore, if the introduction of smart city technologies, facilities, and services aims to revitalize established old cities rather than to seek large-scale development projects, priority should be assigned to the introduction of proper technologies for enhancing citizens' safety, comfort, and convenience so as to heighten their quality of life, rather than to the competition between advanced technologies.

In the analysis of each city, factors affecting citizens' preference for smart city projects showed differences. In the case of Jochiwon, the age $(t=-2.652, p=0.000)$ and monthly income $(t=-2.919$, $p=0.009$ ) were found to have a negative correlation with preference regarding a smart city project. Other independent variables on satisfaction with living conditions-residence $(t=-10.581, p=0.000)$, health $(t=-4.079, p=0.000)$, urban environments and infrastructure $(t=-10.866, p=0.000)$, and safety issues $(t=-7.781, p=0.000$ ) -also showed a negative correlation with residents' preference. This result could indicate that preference level regarding smart cities could be affected by citizens low satisfaction with quality of life.

Therefore, it is safe to say that citizens recognize smart cities as a means of improving their overall living circumstances. In addition, safety control and management services for women, the elderly, and children $(t=-12.202, p=0.000)$ as well as a project to develop a knowledge industrial complex $(t=-9.883, p=0.000)$ also had a high positive correlation with the dependent variable. The real-time city control service, energy reduction, power management technologies $(t=-2.616, p=0.010)$ as well as traffic and pedestrian-related facilities, such as smart traffic control and providing shade $(t=-2.950$, $p=0.004)$, had a positive correlation with the dependent variable, though they were proved to be insignificant in the integrated analysis involving all three cities. These results could be attributed to the fact that some basic infrastructures in Jochiwon were built along with large-scale apartments and housing complexes constructed after 2010, so, compared to the two other cities, it has experienced less aging. These results could also be affected by the fact that the Jochiwon analysis involved a greater number of respondents in the 20 to 40 years age group, who are relatively tech-savvy; however, further research is necessary for confirming this linkage.

Unlike the results for Jochiwon and the aggregate ones, the Cheonan analysis showed that, among the demographic and economic characteristics, only gender $(t=-4.515, p=0.000)$ was significant; furthermore, quality of life was significant for all variables except health. Unlike other cities, however, eco-friendly transportation $(t=-2.261, p=0.025)$ showed negative correlations with the dependent variable in the service sector. Given that Cheonan has a mixture of relatively quiet, dense, low-rise residential and commercial areas and that its central commercial street and a metropolitan railway station are located at the center of the target area, the results could reflect residents' negative views on traffic. Here, the control of and crackdown on crimes, fire, and illegal parking $(t=4.750, p=0.000)$, and safety control and management services for women, the elderly, and children $(t=-3.993, p=0.000)$ had high scores compared to other variables. Factoring in the physical context of the site, where residential and commercial areas are merged, demand for welfare facilities for residents $(t=-2.658, p=0.009)$ and public Wi-Fi $(t=2.273, p=0.024)$ had effects on the dependent variable.

In the case of Pohang, which harbors a concentrated but underdeveloped commercial area, the evaluation of citizens' quality of life regarding gender, age, residential circumstances $(t=-6.952$, $p=0.000)$, and urban infrastructures $(t=-5.225, p=0.000)$ was negatively correlated with the dependent variable, thus showing similarities with the results mentioned above. In addition, the monitoring of and the crackdown on fire, crimes, and illegal parking $(t=5.805, p=0.000)$, and the creation of knowledge industrial complexes $(t=-3.989, p=0.000)$ were found to affect the dependent variable, as was the case in other cities. The demand for the introduction of energy reduction and power management facilities $(t=2.132, p=0.034)$ had a positive correlation with the dependent variable, and the introduction of smart street lamps and trash cans $(t=-3.020, p=0.003)$ had a negative correlation, as in Jochiwon. As for the element of tourism-related facilities, which was found to be significant 
for the aggregate analysis but insignificant for other cities, a negative correlation with the dependent variable was detected with a relatively large value $(t=-4.270, p=0.000)$. This indicates that the introduction of technologies, facilities, and services related to the tourism industry is at odds with citizens' expectations regarding a smart city project. Thus, in this context, it is advisable for Pohang to use such projects as a means of resolving existing issues—rather than focusing on tourism-in order to elicit citizens' interests and garner support.

Thus, analysis results using the regression model showed some similarities, but factors that influenced smart city project-related preferences could differ in accordance with diverse urban conditions and backgrounds. Such differences can be caused by a variety of elements including each city's physical, social, and environmental features and quality of life. Given that this research reviewed citizens' opinions, which are hard to predict through the simple comparison of the scores accrued by each technology, facility, and service, in particular, this model is expected to be used as a useful tool for public entities to systematically collect citizens' opinions when pushing for future smart city projects.

\section{Discussion and Implications}

This study selected smart city technologies, facilities, and services that could be introduced into existing old cities, chose three areas where related projects are to be implemented, and collected the residents' opinions regarding smart cities. This research partially determined that citizens residing in old cities expected smart city businesses to help them improve their living circumstances and to ensure safety and security.

The literature review of this study highlighted the significance of citizen-centric smart cities as a means of improving residents' quality of life. For its evaluation, proper items were selected and analyzed. South Korea's urban regeneration projects and policy guidelines call for the preservation of the physical, social, and economic contexts of any given region. Therefore, this research chose technologies, facilities, and services that would have little effect on existing urban infrastructures, as determined through evaluations by experts. This study evaluated citizens' assessments regarding their life quality and reviewed preferences for each item (in the categories of technologies, facilities, and services) and for smart city business plans. By doing so, this study aimed to establish a basis for researches focusing on citizens. In fact, study results showed that citizens preferred smart city projects as a means of improving their quality of life and boosting convenience through the enhancement of urban infrastructures, among other things. Based upon these findings, this study presented detailed directions for a smart city to meet the demand of its actual users (as highlighted by earlier researches). It also tried to figure out what citizens really expected from smart city projects, as previous researchers seem to have paid little attention to this issue. The analysis results found that citizens preferred services that were closely linked to their everyday lives, rather than the introduction of any new "wow factor" services; these included crime prevention, safe environments for pedestrians, and free Wi-Fi.

However, this study had one limitation in that only three places were examined; this obstructed a clear identification of relations between citizens' opinions and the physical features of each city, even though the three research sites could be considered as so called representative cities for "Smart Urban Regeneration" in South Korea. The research model employed here may also not function as an absolute standard that can be accepted internationally, since each city has different conditions and circumstances.

To overcome these limitations, further research should be conducted to comprehensively assess smart city projects at different sites by factoring in their scope and budget and citizens' characteristics. Many countries have introduced legislation calling for a greater role for citizens' voices in implementing urban planning projects; however, most such moves employ top-down approaches rather than bottom-up approaches and tend to focus on persuading residents to accept the authorities' measures. In particular, for such projects in established cities, technology-driven ways tend to be quite common in reality, and few legal and systematic frameworks promote citizens' participation, listen to their opinions, and carry out post-implementation evaluations. It is only lately that analysis models for the 
post evaluation of those projects have come under review. Therefore, it is necessary for public entities to establish legal and institutional measures to better reflect citizens' opinions during the early stages of related projects and to devise a standardized system. All in all, this study has important implications in that it presented a basic framework that can be used for listening to citizens and for evaluating their opinions in an efficient manner when implementing similar future projects; furthermore, it partially verified the tool through an analysis of actual project sites.

Funding: This research is supported by Korea Agency for Infrastructure Technology Advancement (KAIA) (20TSRD-B151228-02) and Korea University Research Center (Q1828501) funded by Urban Insight Korea Co., Ltd.

Conflicts of Interest: The author declares no conflict of interest.

\section{References}

1. Cardullo, P.; Kitchin, R. Being a 'citizen'in the smart city: Up and down the scaffold of smart citizen participation in Dublin, Ireland. GeoJournal 2019, 84, 1-13. [CrossRef]

2. Peng, G.C.A.; Nunes, M.B.; Zheng, L. Impacts of low citizen awareness and usage in smart city services: The case of London's smart parking system. Inf. Syst. e-Bus. Manag. 2017, 15, 845-876. [CrossRef]

3. Jalali, R.; El-Khatib, K.; McGregor, C. Smart City Architecture for Community Level Services through the Internet of Things. In Proceedings of the 2015 18th International Conference on Intelligence in Next Generation Networks, Paris, France, 17-19 February 2015; pp. 108-113.

4. Anthopoulos, L.G.; Vakali, A. Urban planning and smart cities: Interrelations and reciprocities. In The Future Internet Assembly; Springer: Berlin/Heidelberg, Germany, 2012; pp. 178-189.

5. Khansari, N.; Mostashari, A.; Mansouri, M. Impacting sustainable behavior and planning in smart city. Int. J. Sustain. Land Use Urban Plan. 2014, 1. [CrossRef]

6. Cassandras, C.G. Smart cities as cyber-physical social systems. Engineering 2016, 2, 156-158. [CrossRef]

7. Hollands, R.G. Will the real smart city please stand up? Intelligent, progressive or entrepreneurial? City 2008, 12, 303-320. [CrossRef]

8. Bakıc1, T.; Almirall, E.; Wareham, J. A smart city initiative: The case of Barcelona. J. Knowl. Econ. 2013, 4, 135-148. [CrossRef]

9. David, B.; Yin, C.; Zhou, Y.; Xu, T.; Zhang, B.; Jin, H.; Chalon, R. SMART-CITY: Problematics, techniques and case studies. In Proceedings of the 2012 8th International Conference on Computing Technology and Information Management (NCM and ICNIT), Seoul, Korea, 24-26 April 2012; pp. 168-174.

10. Komninos, N.; Pallot, M.; Schaffers, H. Special issue on smart cities and the future internet in Europe. J. Knowl. Econ. 2013, 4, 119-134. [CrossRef]

11. Allam, Z.; Dhunny, A.Z.; Siew, G.; Jones, D.S. Towards smart urban regeneration: Findings of an urban footprint survey in Port Louis, Mauritius. Smart Cities 2018, 1, 121-133. [CrossRef]

12. Carter, D. Urban regeneration, digital development strategies and the knowledge economy: Manchester case study. J. Knowl. Econ. 2013, 4, 169-189. [CrossRef]

13. Bezplyug, E.; Afonina, V.; Grosheva, A. Smart city and heritage preservation with the help of modern technologies. In Russian Economy: Goals, Challenges and Achievements. Сборник НаучныхСтатейСтудентов Бакалавриата Магистратуры; Научные технологии: Moscow, Russia, 2018; p. 30.

14. Angelidou, M.; Karachaliou, E.; Angelidou, T.; Stylianidis, E. Cultural heritage in smart city environments. Int. Arch. Photogramm. Remote Sens. Spat. Inf. Sci. 2017, 42, 27-32. [CrossRef]

15. Cameron, J.; Grant-Smith, D. Building citizens: Participatory planning practice and a transformative politics of difference. Urban Policy Res. 2005, 23, 21-36. [CrossRef]

16. Nam, T.; Pardo, T.A. Smart city as urban innovation: Focusing on management, policy, and context. In Proceedings of the 5th International Conference on Theory and Practice of Electronic Governance, Tallinn, Estonia, 26-28 September 2011; pp. 185-194.

17. Odendaal, N. Information and communication technology and local governance: Understanding the difference between cities in developed and emerging economies. Comput. Environ. Urban Syst. 2003, 27, 585-607. [CrossRef]

18. Macke, J.; Casagrande, R.M.; Sarate, J.A.R.; Silva, K.A. Smart city and quality of life: Citizens' perception in a Brazilian case study. J. Clean. Prod. 2018, 182, 717-726. [CrossRef] 
19. Capdevila, I.; Zarlenga, M. Smart city or smart citizens? The Barcelona case. J. Strategy Manag. 2015, 8, 266-282. [CrossRef]

20. Myers, D. Building knowledge about quality of life for urban planning. J. Am. Plan. Assoc. 1988, 54, 347-358. [CrossRef]

21. Pacione, M. Urban environmental quality and human wellbeing-A social geographical perspective. Landsc. Urban Plan. 2003, 65, 19-30. [CrossRef]

22. De Hollander, A.E.; Staatsen, B.A. Health, environment and quality of life: An epidemiological perspective on urban development. Landsc. Urban Plan. 2003, 65, 53-62. [CrossRef]

23. Ameen, R.F.M.; Mourshed, M. Society, Urban sustainability assessment framework development: The ranking and weighting of sustainability indicators using analytic hierarchy process. Sustain. Cities Soc. 2019, 44, 356-366. [CrossRef]

24. Lee, Y.J. Environment, Subjective quality of life measurement in Taipei. Build. Environ. 2008, 43, $1205-1215$. [CrossRef]

25. Hick, D.; Urban, A.; Noennig, J.R. A pattern logic for a citizen-generated subjective quality of life index in neighborhoods. In Proceedings of the 2019 IEEE 2nd Ukraine Conference on Electrical and Computer Engineering (UKRCON), Lviv, Ukraine, 2-6 July 2019; pp. 1282-1286.

26. Seik, F.T. Subjective assessment of urban quality of life in Singapore (1997-1998). Habitat Int. 2000, 24, 31-49. [CrossRef]

27. Pazhuhan, M.; Shahraki, S.Z.; Kaveerad, N.; Cividino, S.; Clemente, M.; Salvati, L.J.S. Factors underlying life quality in urban contexts: Evidence from an industrial city (Arak, Iran). Sustainability 2020, 12, 2274. [CrossRef]

28. Von Wirth, T.; Grêt-Regamey, A.; Stauffacher, M. Mediating effects between objective and subjective indicators of urban quality of life: Testing specific models for safety and access. Soc. Indic. Res. 2015, 122, 189-210. [CrossRef]

29. Doost Mohammadian, H.; Rezaie, F.J.I. Sustainable Innovative Project Management: Response to Improve Livability and Quality of Life: Case Studies: Iran and Germany. Inventions 2019, 4, 59. [CrossRef]

30. Nevado-Peña, D.; López-Ruiz, V.R.; Alfaro-Navarro, J. Improving quality of life perception with ICT use and technological capacity in Europe. Technol. Forecast. Soc. Chang. 2019, 148, 119734. [CrossRef]

31. D'Acci, L. Monetary, subjective and quantitative approaches to assess urban quality of life and pleasantness in cities (hedonic price, willingness-to-pay, positional value, life satisfaction, isobenefit lines). Soc. Indic. Res. 2014, 115, 531-559. [CrossRef]

32. Van Kamp, I.; Leidelmeijer, K.; Marsman, G.; De Hollander, A. Urban environmental quality and human well-being: Towards a conceptual framework and demarcation of concepts; a literature study. Landsc. Urban Plan. 2003, 65, 5-18. [CrossRef]

33. Wasserman, I.M.; Chua, L.A. Objective and subjective social indicators of the quality of life in American SMSA's: A reanalysis. Soc. Indic. Res. 1980, 8, 365-381. [CrossRef]

34. Zakerhaghighi, K.; Khanian, M.; Gheitarani, N. Subjective quality of life; assessment of residents of informal settlements in Iran (a case study of Hesar Imam Khomeini, Hamedan). Appl. Res. Qual. Life 2015, 10, 419-434. [CrossRef]

35. Schulz, W. Explaining Quality of Life: The Controversy between Objective and Subjective Variables; Paul Lazarsfeld-Gesellschaft für Sozialforschung (PLG): Wien, Austria, 2000.

36. Mitchell, G. Indicators as tools to guide progress on the sustainable development pathway. In Sustaining Human Settlement: A Challenge for the New Millennium; Lawrence, J.R., Ed.; Urban International Press: North Shields, UK, 2000; pp. 55-104.

37. Carli, R.; Dotoli, M.; Pellegrino, R.; Ranieri, L. Measuring and managing the smartness of cities: A framework for classifying performance indicators. In Proceedings of the 2013 IEEE International Conference on Systems, Man, and Cybernetics, Manchester, UK, 13-16 October 2013; pp. 1288-1293.

38. Lee, J.H.; Phaal, R.; Lee, S.H. An integrated service-device-technology roadmap for smart city development. Technol. Forecast. Soc. Chang. 2013, 80, 286-306. [CrossRef]

39. Lytras, M.D.; Visvizi, A. Who uses smart city services and what to make of it: Toward interdisciplinary smart cities research. Sustainability 2018, 10, 1998. [CrossRef]

40. Chang, C.I.; Lo, C.C. Planning and implementing a smart city in Taiwan. IT Prof. 2016, 18, 42-49. [CrossRef]

41. Angelidou, M. Smart city policies: A spatial approach. Cities 2014, 41, S3-S11. [CrossRef] 
42. Suau, C.; Zappulla, C. Recovering grand urbanism: Ecological landscape, wetlands and phytodepuration in Magok Park, Seoul. J. Multidiscip. Eng. Sci. Technol. 2015, 2, 2947-2953.

43. Madakam, S.; Holmukhe, R.M. Songdo Smart City: An Aerotropolis and a Ubiquitous City. In Big Data Analytics for Smart and Connected Cities; IGI Global: Hershey, PA, USA, 2019; pp. 278-298.

44. Evans, J.; Karvonen, A.; Raven, R. The Experimental City; Routledge: Abingdon-on-Thames, UK, 2016.

45. Kim, H.K.; Yi, M.S.; Shin, D.B. Regional diffusion of smart city service in South Korea investigated by spatial autocorrelation: Focused on safety and urban management. Spat. Inf. Res. 2017, 25, 837-848. [CrossRef]

46. The Vision and Strategies for Smart City Seoul in the Area of 4th Industrial Revolution. Available online: https://www.si.re.kr/node/62142 (accessed on 20 July 2020).

47. Smart City Urban Regenerations. Available online: https://smartcity.go.kr/\%EC\%A0\%95\%EC\%B1\%85/ $\%$ EC $\%$ A0\%95\%EC\%B1\%85\%EC\%82\%AC \%EC \%97\%85/\%EC\%8A\%A4\%EB\%A7\%88\%ED\%8A\%B8\%EB\% 8F\%84\%EC\%8B\%9C\%ED\%98\%95-\%EB\%8F\%84\%EC\%8B\%9C\%EC\%9E\%AC\%EC\%83\%9D/ (accessed on 10 July 2020).

48. Saaty, T.L. Fundamentals of Decision Making and Priority Theory with the Analytic Hierarchy Process; RWS Publications: Pittsburgh, PA, USA, 2000; Volume 6.

49. Baptiste, A.K.; Foley, C.; Smardon, R. Understanding urban neighborhood differences in willingness to implement green infrastructure measures: A case study of Syracuse, NY. Landsc. Urban Plan. 2015, 136, 1-12. [CrossRef]

50. Maas, C.J.; Hox, J.J. Robustness issues in multilevel regression analysis. Stat. Neerl. 2004, 58, $127-137$. [CrossRef]

51. Willms, J.D. Basic concepts in hierarchical linear modeling with applications for policy analysis. In Handbook of Educational Policy; Elsevier: Amsterdam, The Netherlands, 1999; pp. 473-493.

52. Announcement of Urban Regeneration Project Site of Korea. Available online: http://m.molit.go.kr/ viewer/skin/doc.html?fn=9398bede49e96eb4e96b4bcd712292e6\&rs=/viewer/result/20171214 (accessed on 11 July 2020).

53. Enforcement Decree of the Special Act on Promotion of and Support for Urban Regeneration. Available online: http://law.go.kr/lsSc.do?section=\&menuId=1\&subMenuId=15\&tabMenuId=81\&eventGubun=060101\& query $=\% \mathrm{~EB} \% 8 \mathrm{~F} \% 84 \% \mathrm{EC} \% 8 \mathrm{~B} \% 9 \mathrm{C} \% \mathrm{EC} \% 9 \mathrm{E} \% \mathrm{AC} \% \mathrm{EC} \% 83 \% 9 \mathrm{D} \#$ undefined (accessed on 16 March 2020).

(C) 2020 by the author. Licensee MDPI, Basel, Switzerland. This article is an open access article distributed under the terms and conditions of the Creative Commons Attribution (CC BY) license (http://creativecommons.org/licenses/by/4.0/). 